Table 1. Univariate predictors of fracture in the smoking cohort * denotes significant prediction

\begin{tabular}{|c|c|c|c|c|}
\hline Predictor & $\begin{array}{l}\text { Fracture } \\
(n=1663)\end{array}$ & $\begin{array}{l}\text { No Fracture } \\
(n=2433)\end{array}$ & $\begin{array}{l}\text { Odds } \\
\text { ratio }\end{array}$ & $95 \% \mathrm{Cl}$ \\
\hline Age (years) & 66.58 & 62.97 & $1.03^{*}$ & $\begin{array}{r}{[1.02} \\
1.03]\end{array}$ \\
\hline Gender (no. of patients) & $\begin{array}{c}\text { Male }(383) \\
\text { Female (1280) }\end{array}$ & $\begin{array}{c}\text { Male (469) } \\
\text { Female (1964) }\end{array}$ & $0.80^{*}$ & $\begin{array}{r}{[0.69} \\
0.93]\end{array}$ \\
\hline Height $(\mathrm{cm})$ & 162.26 & 162.41 & 1.00 & $\begin{array}{c}{[0.99} \\
1.01]\end{array}$ \\
\hline Weight (kg) & 71.16 & 71.16 & 1.00 & $\begin{array}{r}{[1.00} \\
1.00]\end{array}$ \\
\hline L1-L4 BMD $\left(\mathrm{g} / \mathrm{cm}^{2}\right)$ & 1.04 & 1.10 & $0.19^{*}$ & $\begin{array}{r}{[0.13} \\
0.26]\end{array}$ \\
\hline $\begin{array}{l}\text { Femoral neck BMD (left) }(\mathrm{g} / \\
\left.\mathrm{cm}^{2}\right)\end{array}$ & 0.82 & 0.87 & $0.08^{*}$ & $\begin{array}{r}{[0.05} \\
0.12]\end{array}$ \\
\hline $\begin{array}{l}\text { Total femur BMD (left) }(\mathrm{g} / \\
\mathrm{cm}^{2} \text { ) }\end{array}$ & 0.87 & 0.92 & $0.10^{*}$ & $\begin{array}{r}{[0.07} \\
0.16]\end{array}$ \\
\hline$\%$ Body fat $(\mathrm{g})$ & 308.15 & 299.89 & $1.00^{*}$ & $\begin{array}{r}{[1.00} \\
1.00] \\
\end{array}$ \\
\hline
\end{tabular}

In the multivariate model, the only variables associated with increased fracture risk was increasing age at scan decreased BMD total left and increased percentage body fat. All other factors did not significantly increase fracture risk in this cohort.

Conclusion: Our study suggests that many risk factors are associated with fragility fractures in those with smoking as their only risk factor; the best predictor was age at scan, BMD and gender. The percentage body fat association with increased fracture risk is quite surprising and would need further study. Percentage body fact is not currently included in the FRAX'TM tool.

Disclosure of Interests: Dominic Beith: None declared, Marwan Bukhari Speakers bureau: Bristol-Myers Squib, UCB celltech, Roche/Chugai, Pfizer, Abbvie, Merck, Mennarini, Sanofi-aventis, Eli-Lilly, Janssen and Novartis. DOI: 10.1136/annrheumdis-2019-eular.2453

\section{FRI0483 \\ INTEREST OF A SYSTEMATIC SCREENING OF OSTEOPOROSIS IN HEART TRANSPLANT PATIENTS}

CORALLI Romain ${ }^{1,1}$, Constance Verdonk ${ }^{2}$, Sebastien Ottaviani ${ }^{1}$, Julia Goossens ${ }^{1}$, Lucie Demaria ${ }^{1}$, Elisabeth Palazzo ${ }^{1}$, Richard Dorent ${ }^{2}$, Philippe Dieudé ${ }^{1}$,

Marine Forien ${ }^{1} .{ }^{1}$ hôpital Bichat, Rheumatology, Paris, France; ${ }^{2}$ hôpital Bichat, Cardiology, Paris, France

Background: Osteoporosis is common among patients with end-stage heart disease. A rapid decrease of bone mineral density (BMD) is usually observed after heart transplantation. Bone loss is probably linked to glucocorticoids and calcineurin inhibitors use and vitamin D deficiency.

Objectives: The aim of this study was to evaluate the interest of a systematic screening of osteoporosis in heart transplant patients.

Methods: We performed a prospective monocentric study including patients, who had of heart transplantation in our hospital, from December 2016 to January 2019.The following parameters were systematically assesses: history of cardiac disease, immunosuppressive therapies, glucocorticoids, previous history of low trauma fracture, known risk factors of osteoporosis, treatment received for bone disease management (calcium, vitamin $\mathrm{D}$ and bisphosphonates). Blood tests with creatinine clearance, calcium and vitamin D levels, were assessed. Bone densitometry and spine radiographs (to search asymptomatic vertebral fractures) were assessed in all patients. Osteoporosis was defined respectively for patients $\geq 50$ years and $<50$ years as a T-score $\leq-2.5$ SD and Z-score $\leq-2$ SD either at lumbar spine (L2-L4), femoral neck or hip.

Results: A total of 42 patients were included $(76.7 \%$ male), mean age was $58.1 \pm 10.6$ years, mean duration after transplantation was $2.6 \pm 3.1$ years. Past or active smoking statues were observed in 26 patients (mean 23.9 pack-years). Calcium, vitamin $\mathrm{D}$ and bisphosphonates were administered in $13(30.9 \%), 10(23.8 \%)$ and one patients, respectively. All patients received prednisone (mean dose: $10.7 \pm 4.9$ per day). Mean lumbar spine BMD was $1.03 \pm 0.25 \mathrm{~g} / \mathrm{cm}^{2}$ and left femoral neck BMD 0.85 $\pm 0.15 \mathrm{~g} / \mathrm{cm}^{2}$. Osteoporosis was observed in $18(45 \%)$ patients. Only one hip fracture was known before heart transplantation. Incidental low trauma fractures after transplantation were diagnosed in 14 patients (33.3\%): 11 patients with vertebral fractures (mean 2 vertebral fractures per patient) including 4 patients with asymptomatic vertebral fractures. Others low trauma fractures were hip fracture, proximal humerus and fibula for one patient each. Mean duration between transplantation and the first low trauma fracture was $7.5 \pm 3.7$ months. Low level of calcemia was found in
20 patients $(47.6 \%)$ and low level of vitamin D $(\leq 30 \mathrm{mg} / \mathrm{l})$ in 32 patients $(76.2 \%)$ associated with secondary hyperparathyroidism in 21 patients $(51.2 \%)$, mean creatinine clearance was $51.7 \pm 19.9 \mathrm{ml} / \mathrm{min}$. After evaluation, specific treatment of osteoporosis was started for 33 patients $(78.6 \%$ ): zoledronic acid $(n=20)$, denosumab $(n=8)$, alendronate $(n=4)$ and teriparatide $(n=1)$.

Conclusion: Systematic screening of osteoporosis seems to be useful in heart transplant patients. Osteoporosis was observed in half of these patients with a high frequency of low trauma fracture after heart transplantation, particularly in the first year.

Disclosure of Interests: None declared

DOI: 10.1136/annrheumdis-2019-eular.7504

\section{FRI0484 RESULTS OF BONE MINERAL DENSITY DURING CELIAC DISEASE: ABOUT 83 CASES}

Cyrine Daldoul, Nejla El Amri, Khadija Baccouch, Hela Zeglaoui, Elyes Bouajina. Farhat Hached Hospital, Rheumatology, Sousse, Tunisia

Background: The prevalence of osteopenia during celiac disease (CD) can range from $38 \%$ to $72 \%$. In fact, it is a pathology that causes bone loss and is associated with a higher fracture risk compared to the general population.

Objectives: The aim of this work is to determine the frequency and factors associated with the decline in bone mineral density in adult subjects with CD.

Methods: This is a retrospective study, over a period of 4 years (from January 2014 to December 2018) and including patients followed for MC who had a measurement of bone mineral density (BMD) by DEXA.

Clinical, anthropometric and densitometric data (BMD at the femoral and vertebral site) were recorded.

The WHO criteria for the definition of osteoporosis and osteopenia have been used.

Results: 83 patients were collected among them 12 were men (sex ratio $=0.16$ ). The average age was 38.2 years old. The average body mass index (BMI) was $21.64 \mathrm{~kg} / \mathrm{m}^{2}$ [13.05-31.9 kg/m²]. Undernutrition (BMI <19 $\mathrm{kg} / \mathrm{m}^{2}$ ) was found in 24 cases. It was associated with hyperthyroidism in 5 cases, autoimmune hepatitis in 1 case and primary amenorrhoea in 2 cases. 2 patients had a history of fragility fracture, and 5 patients had a history of fragility fracture in a first-degree relative.

Osteodensitometry showed low bone mass in 36 cases: osteoporosis in 23 patients $(27.7 \%)$ and osteopenia in 13 cases. Osteoporosis was found in 21 patients: 1 man and 20 women. Mean femoral BMD was $0.887 \mathrm{~g} /$ $\mathrm{cm} 3$ and vertebral BMD was $0.999 \mathrm{~g} / \mathrm{cm} 3$. The mean T-score at the femoral site and the vertebral site were -1.28 SD and -1.26 SD, respectively. No correlation was found between age and BMD and bone status. Comparing patients with a BMI $<19 \mathrm{~kg} / \mathrm{m}^{2}$ to those with a BMI $\geq 19 \mathrm{~kg} /$ $\mathrm{m}^{2}$, BMD at the vertebral site was significantly lower in malnourished subjects $(p=0.01)$. a significant correlation was found between BMI and vertebral BMD $(p=0.000)$

Conclusion: The decline in BMD was observed in third of our patients. It seems to be favored by a low BMI, which is common during CD in relation to the associated malabsorption. Thus, screening for osteoporosis should be advocated early in the course of $C D$.

Disclosure of Interests: None declared

DOI: 10.1136/annrheumdis-2019-eular.8265

\section{FRI0485 TIMED UP AND GO TEST FOR VERTEBRAL FRACTURE PREDICTION}

Cyrine Daldoul ${ }^{1}$, Nejla El Amri ${ }^{1}$, Khadija Baccouch ${ }^{1}$, Amine Kalai $^{2}$, Mohamed Amine Triki ${ }^{3}$, Hela Zeglaoui ${ }^{1}$, Elyes Bouajina ${ }^{1} .{ }^{1}$ Farhat Hached Hospital, Rheumatology, Sousse, Tunisia; ${ }^{2}$ Fattouma Bourguiba Hospital, Rehabilitation, Monastir, Tunisia; ${ }^{3}$ Sahloul Hospital, Orthopaedic Surgery, Sousse, Tunisia

Background: Sarcopenia describes the age related loss of skeletal mus cular mass and function. The development of sarcopenia may confer an increased risk of falls which leads to a potential increase in fracture. The Timed Up and Go (TUG) Test is one of clinical tools used to assess sarcopenia.

Objectives: We hypothesized that slow TUG test performance would predict vertebral fracture (VF) in post-menopausal women independently of bone mineral density (BMD) and other risk factors.

Methods: This is a cross sectional study enrolled from September 2018 to December 2018, including post-menopausal women referred to rheumatology department for measure of BMD. All subjects underwent dual energy X-ray absorptiometry (DeXA) and physical performance tests 
including the TUG test. TUG performance was considered low if it took, 15 seconds or longer. A vertebral fracture assessment (VFA) image was obtained which was subsequently scored for the presence of significant vertebral deformities. VF grade 1 were excluded.

Results: Eighty four patients were included. The mean age of our patients was $62.29 \pm 8.27$ years with an average body mass index (BMI) of $31.45 \pm 6.21 \mathrm{~kg} / \mathrm{m}^{2}$ [18.18-44.38]. According to the WHO classification 42 patients $(50 \%)$ had osteoporosis. Among 84 women, 47 had a low TUG performance. Subjects with low TUG performance had an older age (57.94 vs 65.71 years) $(p<0.001)$, and had a significantly lower BMD at femoral neck $\left(0.825 \mathrm{~g} / \mathrm{cm}^{3} v s \quad 0.752 \mathrm{~g} / \mathrm{cm}^{3}\right) \quad(p<0.001)$. There was no significant difference between the two groups regarding duration of menopause, history of previous fragility fracture, body mass index and BMD at total hip and at vertebral site. Osteoporosis was found in 30 patients who had low TUG performance and in 12 patients who had normal TUG performance without statistically significant difference $(p=0.08)$.VF were assessed in 22 subjects. VF were found in 20 patients with low TUG performance $(42.55 \%)$. Compared with the group with normal TUG performance, subjects with low TUG performance had significantly higher number of fracture $(p<0.001)$.A significant correlation was found between the number of VF and the score of get up and go test (Khi-2 test, $\mathrm{p}<0.001)$.

Conclusion: Our study found a strong relationship between TUG performance and prevalent vertebral fracture. Therefore evaluation of additional risk factors may improve the prediction of vertebral fracture in post-menopausal women.

Disclosure of Interests: None declared

DOI: 10.1136/annrheumdis-2019-eular.6377

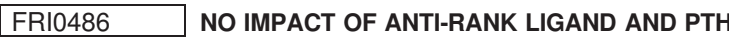 ANALOGUES ON CARDIOVASCULAR RISK IN IDIOPATHIC AND POSTMENOPAUSAL OSTEOPOROSIS: A SYSTEMATIC LITERATURE REVIEW AND META- ANALYSIS}

Laurence Ferrieres, Yannick Degboe, Michel Laroche, Arnaud Constantin, Adeline Ruyssen-Witrand. Hospital Center University Toulouse - Casselardit Ancely, Toulouse, France

Background: Emerging evidence suggests a possible association between osteoporosis and cardiovascular disease ${ }^{1,2}$. The mutual effects of drugs used in these two diseases are now a point of interest. Two meta-analyses have been conducted to explore the cardiovascular effects of bisphosphonates $^{3,4}$. There is no review for other osteoporosis treatments, such as anti-rank ligand antibody and parathyroid hormone analogues.

Objectives: A literature review and meta-analysis of randomized controlled trials was conducted to address the impact of PTH analogues and antiRank Ligand on cardiovascular events and overall mortality in individuals with idiopathic osteoporosis

Methods: A systematic literature review was conducted in December 2017 in the PubMed, Embase, Cochrane databases, and updated on PubMed in December 2018, by selecting trials including a treatment (antiRank Ligand or PTH analogue) and a control group. We also conducted a search for abstracts of the French Rheumatology Society, American College of Rheumatology and European League Against Rheumatisms annual meetings over the past 3 years. Relative risks and 95\% confidence intervals for each event were estimated using the Inverse Variance fixed effects method. The main endpoints were the occurrence of cardiovascular events and all-cause of mortality.

Results: Of the 2782 reports initially found (503 articles via PubMed, 1309 via Embase, 474 via the Cochrane Library and 15 abstracts from annual meetings, 16 articles were used for the meta-analysis. All studies were randomized; no exploitable prospective cohort study was found. The number of adverse events of interest was available for 6 studies for the anti-Rank Ligand corresponding to 26864 patient-years. After meta-analysis, there was no significant difference between the placebo group and the anti-Rank Ligand group for overall mortality (RR $0.79,95 \% \mathrm{Cl}(0.60$ 1.04)), the combined cardiovascular endpoint (overall mortality, coronary artery disease and stroke: $\mathrm{RR} 0.95,95 \% \mathrm{Cl}(0.78-1.16))$, and the individual risk of coronary artery disease (RR 1.14, 95\% Cl (0.76-1.73)), arrhythmia (RR 1.03, 95\% Cl $(0.63-1.68)$ ) and ischemic or hemorrhagic stroke (RR $1.03,95 \% \mathrm{Cl}(0.72-1.47)$ ). The number of adverse events of interest was available for 10 studies for the PTH analogue group, corresponding to 6220 patient-years. After meta-analysis, there was no significant difference between the placebo group and the PTH analogue group for overall mortality ( $\mathrm{RR} 0.89,95 \% \mathrm{Cl}(0.35-2.29)$ ), the combined endpoint (overall mortality, coronary artery disease and stroke: RR 0.71 , 95\% $\mathrm{Cl}(0.37-1.36)$ ), and the individual risk of coronary artery disease (RR
$0.65,95 \% \mathrm{Cl}(0.19-2.27)$ ), arrhythmia disorders (RR 1.43, 95\% Cl (0.73$2.80)$ ) and ischemic or hemorrhagic stroke (RR $0.60,95 \% \mathrm{Cl}(0.19-1.96)$ ). Conclusion: The anti-Rank Ligand and the PTH analogues have no short-term impact on the cardiovascular risk and the overall mortality in postmenopausal osteoporosis. To better answer the question whether these treatments are able to reduce the long-term cardiovascular risk, further comparative studies with longer duration are required.



REFERENCES:

[1] von der Recke P, et al. The association between low bone mass at the menopause and cardiovascular mortality. Am J Med. 1999;106(3):273-278.

[2] Veronese $\mathrm{N}$, et al. Relationship Between Low Bone Mineral Density and Fractures With Incident Cardiovascular Disease: A Systematic Review and Meta-Analysis. J Bone Miner Res Off J Am Soc Bone Miner Res. 2017;32 (5):1126-1135

[3] Kim DH, et al. Bisphosphonates and Risk of Cardiovascular Events: A Meta-Analysis. Pizzi C, ed. PLOS ONE. 2015;10(4):e0122646.

[4] Kranenburg $G$, et al. Bisphosphonates for cardiovascular risk reduction: A systematic review and meta-analysis. Atherosclerosis. 2016;252:106-115.

Disclosure of Interests: None declared

DOI: 10.1136/annrheumdis-2019-eular.2032

\section{FRI0487 UTILITY OF TRABECULAR BONE SCORE(TBS) FOR FRACTURE RISK ASSESSMENT IN GLUCOCORTICOID- INDUCED OSTEOPOROSIS}

Helena Florez ${ }^{1}$, José Hernández-Rodríguez ${ }^{2}$, Africa Muxi ${ }^{3}$, Josep Lluís Carrasco ${ }^{4}$, Sergio Prieto-González ${ }^{2}$, Silvia Ruiz-Gaspà ${ }^{1}$, Maria C. Cid ${ }^{2}$, Ana Monegal', Núria Guañabens ${ }^{1}$, Pilar Peris ${ }^{1} .{ }^{1}$ Hospital Clinic, University of Barcelona, Metabolic Bone Diseases Unit. Department of Rheumatology, Barcelona, Spain; ${ }^{2}$ Hospital Clínic, University of Barcelona, Institut d'Investigacions Biomèdiques August Pi i Sunyer (IDIBAPS), Vasculitis Research Unit, Department of Autoimmune Diseases, Barcelona, Spain; ${ }^{3}$ Hospital Clinic, University of Barcelona, Department of Nuclear Medicine, Barcelona, Spain; ${ }^{4}$ University of Barcelona, Biostatistics, Department of Basic Clinical Practice, Barcelona, Spain

Background: Glucocorticoid-induced osteoporosis (GIOP) is the one of the most common forms of secondary osteoporosis (OP). Fractures in GIOP frequently occur with higher than expected bone mineral density (BMD) values. The Trabecular Bone Score (TBS) is a gray-level textural index derived from DXA images that provides information about bone microarchitecture and fracture risk independently of BMD; therefore, TBS measurement could be useful for identifying patients with high fracture risk associated with glucocorticoid (GC) treatment.

Objectives: To analyse the clinical utility of TBS for fracture risk assessment in GC treated patients and compare it with BMD assessment, the gold-standard diagnostic test.

Methods: 127 patients on chronic GC treatment $(\geq 5 \mathrm{mg} /$ day) were included (mean age $62 \pm 18$ years, $63 \%$ women) in this cross-sectional study. The medical history and anthropometric data were collected, as well as measurements of bone metabolism parameters, bone densitometry (DXA) at lumbar spine and femur (considering OP when T-score $\leq-2.5$ ) TBS (considering degraded microarchitecture [DMA] with values <1.230) and dorsolumbar $\mathrm{X}$-ray to assess vertebral fractures (VF). BMD and TBS 